\title{
Impact of Chronicity on Lipid Profile of Type 2 Diabetics
}

\author{
Singh $^{1}$, Gurdeep \& Kumar ${ }^{2}$, Ashok \\ ${ }^{1}$ Ph.D. Research Scholar, Department of Sports Science, Punjabi University Patiala, India, Email: \\ drgurdeep_sahni@yahoo.co.in \\ ${ }^{2}$ Assistant Professor, Department of Sports Science, Punjabi University Patiala, India
}

\section{Abstract}

Aim: To study the impact of chronicity of type 2 diabetes on lipid profile in type 2 diabetics. Material \& Methods: This study was conducted on 120 Punjabi male type 2 diabetics. Their age ranged from 30 to 70 years. The subjects were categorized into three groups, on the basis of the duration of detection of type 2 diabetes- group 1(below 4 years), group 2 (between 4 to 8 years) and group 3(above 8 years).Results: There was sharp and definite increase in the percentage of patients having $>200 \mathrm{mg} / \mathrm{dl}$ total cholesterol after four years of diabetes mellitus from $16 \%$ to $25 \%$ and then to $55 \%$ after 8 years of duration. The percentage of patients having $>150 \mathrm{mg} / \mathrm{dl}$ of low density lipoproteins (LDL) after 8 years of diabetes mellitus was much high $(67 \%)$ as compared to group $1(29 \%)$ and group $2(49 \%)$. There was also an increase in the percentage of patients having $<160 \mathrm{mg} / \mathrm{dl}$ of triglycerides after four years of diabetes mellitus from $14 \%$ to $37 \%$ of diabetes and then to $56 \%$ after 8 years. Conclusion: The chronicity of Type 2 Diabetes mellitus disturb the normal levels of lipid profile that is dyslipidemia if unchecked this may lead to atherosclerosis and ultimately Cardio-Vascular Disease (CVD) and it is the commonest cause of death in type 2 diabetics.

Key words: Type 2 Diabetes Mellitus, Lipid profile, Dyslipidemia.

\section{Introduction}

Dyslipidemia is one of the major cardiovascular disease (CVD) risk factors and plays an important role in the progress of atherosclerosis, the underlying pathology of CVD. The prevalence of dyslipidemia in type 2 diabetes is double with respect to the general population (Haffner, 1998). In patients with type 2 diabetes, which is equivalent to $\mathrm{CHD}$ (Juutilainen et al. 2005); it is most commonly characterized by elevated $\mathrm{TG}$ and reduced HDL-C (Goldberg, 2001). These abnormalities can be present alone or in combination with other metabolic disorders. The prevalence of dyslipidemia varies depending on the population studied, geographic location, socioeconomic development and the definition used (Wood et al, 1972; Berrios et al, 1997). Triglyceridemia has been associated with increased risk of coronary heart disease both in non-diabetic and type 2 diabetic subjects (Frank et al., 2002, Sridhar, 2002). Remnants of triglyceride rich lipoproteins seem to be extremely atherogenic (Car et al., 2004). LDL cholesterol is related to life style factors such as diet and exercise (Khatit et al., 2008). It has been associated with metabolic syndrome (Analava et al., 2007). The Pro-atherogenic properties of small LDL particles may relate to their ability to penetrate the arterial wall and thereby making them more susceptible to 
oxidation, indirectly linked with coronary artery disease (Goldfine and Beckman, 2008). Coronary artery disease represents a wide spectrum from angina pectoris, myocardial infarction and sudden death to silent myocardial ischemia (Mozaffarian et al., 2006). Silent myocardial ischemia has a reported prevalence of $10-20 \%$ in diabetic population as compared to $1-4 \%$ in non-diabetic population (Ronald et al., 2004). The present study was planned to identify the impact of Chronicity on lipid profile among type 2 diabetic Punjabi population.

\section{Material and Methods}

This prospective study was conducted on 120 type 2 diabetic patients. The age limit was taken from 30 to 70 years. Only male patients were selected on random base as subjects. The study protocol was reviewed and approved by the Ethics Committee of Punjabi University, Patiala. Following exclusion criteria was usedpatients with type 1 diabetes mellitus, any liver, kidney or cardiac failure, neoplasm and patients who were on any type of antilipidemic therapy. The objectives of the present study were thoroughly explained to the subjects. Participants of the study were divided into three groups according to the duration of detection of diabetes mellitus. In the first group patients with history of type 2 diabetes mellitus below 4 years were included; second group included 4-8 years and third group included above 8 years duration of type 2 diabetes mellitus. The patient underwent a clinical assessment, which included history (a questionnaire) and clinical examination. The variables of questionnaire were age, sex, marital status, personal history (occupation, education, socio-economic status) exercise status, smoking status and family history (including family history of diabetes). The serum was separated immediately after obtaining the blood sample (overnight fasting) using centrifugation for 10 minutes. Lipid Profile [Total Cholesterol (TC), HDL \& Triglycerides (TG)] were measured using Blood Analyzer by the qualified laboratory technician. The appropriate chemical testing kits were used. LDL was calculated by using Friedewald formula: $\mathrm{LDL}=\mathrm{TC}-$ (TG/5) - HDL.

\section{Results \& Discussion}

Among 120 patients with diabetes below 4 years of onset, $21(\mathbf{4 8 \%})$ had total cholesterol levels $<150 \mathrm{mg} / \mathrm{dl}$ while $16(36 \%)$ had total cholesterol levels 150 $200 \mathrm{mg} / \mathrm{dl}$ and $7(16 \%)$ had $>200 \mathrm{mg} / \mathrm{dl}$. Among those with diabetes for 4-8 years, $15(30 \%)$ had total cholesterol $<150 \mathrm{mg} / \mathrm{dl}$ while $12(25 \%)$ had $150-200 \mathrm{mg} / \mathrm{dl}$ and 22(45\%) had levels >200mg/dl. Among those with diabetes for above 8 years, $5(19 \%)$ had total cholesterol levels < $150 \mathrm{mg} / \mathrm{dl}$ while $7(26 \%)$ had $150-200 \mathrm{mg} / \mathrm{dl}$ and $15(\mathbf{5 5 \%})$ had $>200 \mathrm{mg} / \mathrm{dl}$.

Among 120 patients with diabetes below 4 years of onset, 10(23\%) had HDL cholesterol levels $<40 \mathrm{mg} / \mathrm{dl}$ while $34(77 \%)$ had $>40 \mathrm{mg} / \mathrm{dl}$. Among those with diabetes for 4-8 years, 19(39\%) had HDL cholesterol $<40 \mathrm{mg} / \mathrm{dl}$ while $30(\mathbf{6 1 \%})$ had $>40 \mathrm{mg} / \mathrm{dl}$. Among those with diabetes for above 8 years, 17(63\%) had HDL cholesterol $<40 \mathrm{mg} / \mathrm{dl}$ while $10(37 \%)$ had $>40 \mathrm{mg} / \mathrm{dl}$.

Among 120 patients with diabetes below 4 years of onset, 31(71\%) had LDL-cholesterol levels $<150 \mathrm{mg} / \mathrm{dl}$ while 
13(29\%) had $>150 \mathrm{mg} / \mathrm{dl}$. Among those with diabetes for $4-8$ years, $25(\mathbf{5 1 \%})$ had LDL cholesterol levels $<150 \mathrm{mg} / \mathrm{dl}$ and 14 24(49\%) had LDL cholesterol >150mg/dl. Among those with diabetes for above 8 years, 9(33\%) had LDL cholesterol $<150$ $\mathrm{mg} / \mathrm{dl}$ while $18(67 \%)$ had LDL cholesterol levels $>150 \mathrm{mg} / \mathrm{dl}$. Among 120 patients with diabetes below 4 years of onset,

Table: Duration of Type 2 diabetes and lipid profile of different groups.

\begin{tabular}{|c|c|c|c|c|c|c|}
\hline Group & \multicolumn{2}{|c|}{ Group 1, (below 4 years) } & \multicolumn{2}{|c|}{ Group 2, (4-8 years) } & \multicolumn{2}{|c|}{ Group 3, (above 8 years) } \\
\hline \multicolumn{7}{|l|}{$\mathrm{TC}(\mathrm{mg} / \mathrm{dl})$} \\
\hline$<150$ & $21(48 \%)$ & $135 \pm 5.9$ & $15(30 \%)$ & $141 \pm 2.2$ & $5(19 \%)$ & $148 \pm 4.1$ \\
\hline $150-200$ & $16(36 \%)$ & $168 \pm 8.2$ & $22(45 \%)$ & $177 \pm 6.9$ & $7(26 \%)$ & $181 \pm 3.3$ \\
\hline$>200$ & $7(16 \%)$ & $202 \pm 2.0$ & $12(25 \%)$ & $214 \pm 3.7$ & $15(55 \%)$ & $222 \pm 5.2$ \\
\hline \multicolumn{7}{|c|}{ HDL (mg/dl) } \\
\hline$<40$ & $10(23 \%)$ & $39 \pm 3.5$ & $19(39 \%)$ & 35 \pm 3.0 & $17(63 \%)$ & $31 \pm 4.2$ \\
\hline$>40$ & $34(77 \%)$ & $52 \pm 5.4$ & $30(61 \%)$ & $47 \pm 2.8$ & $10(37 \%)$ & $44 \pm 3.6$ \\
\hline \multicolumn{7}{|c|}{ LDL (mg/dl) } \\
\hline$<150$ & $31(71 \%)$ & $121 \pm 4.1$ & $25(51 \%)$ & $134 \pm 5.4$ & $9(33 \%)$ & $140 \pm 2.0$ \\
\hline$>150$ & $13(29 \%)$ & $145 \pm 7.2$ & $24(49 \%)$ & $157 \pm 3.9$ & $18(67 \%)$ & $169 \pm 4.7$ \\
\hline \multicolumn{7}{|l|}{ TG (mg/dl) } \\
\hline $40-160$ & $38(86 \%)$ & $120 \pm 7.2$ & $31(63 \%)$ & $143 \pm 3.7$ & $12(44 \%)$ & $147 \pm 5.3$ \\
\hline$>160$ & $6(14 \%)$ & $160 \pm 2.9$ & $18(37 \%)$ & $171 \pm 4.7$ & $15(56 \%)$ & $183 \pm 2.0$ \\
\hline
\end{tabular}

TC- total cholesterol, HDL- high density lipoproteins, LDL-low density lipoproteins, TG- triglycerides

The Patients with diabetes have a higher degree of atherosclerosis burden due to dyslipidemia than the people without diabetes (Mohsin et al., 2007). New National Cholesterol Education Programme (NCEP) guidelines raise the risk factors of patients with diabetes without known CHD to CHD equivalent, a guideline substantiated by the results of numerous studies (Alexander et al., 2003). For example in Finnish East West Study, patients with diabetes, without known heart disease had $20 \%$ chance of having a cardiac event over a 7 years time period $38(\mathbf{8 6 \%})$ had triglyceride levels from 40 $160 \mathrm{mg} / \mathrm{dl}$ while $6(14 \%)$ had $>160 \mathrm{mg} / \mathrm{dl}$. Among those with diabetes for 4-8 years, $31(63 \%)$ had triglycerides from 40-160 $\mathrm{mg} / \mathrm{dl}$ while $18(37 \%)$ had $>160 \mathrm{mg} / \mathrm{dl}$. Among those with diabetes for above 8 years, 12(44\%) had triglycerides 40-160 $\mathrm{mg} / \mathrm{dl}$ while $15(\mathbf{5 6 \%})$ had $>160 \mathrm{mg} / \mathrm{dl}$. 
lipoprotein and triglycerides. Our study is consistent with that.

Conclusion: The chronicity of Type 2 Diabetes mellitus can disturb the normal levels of lipid profile which can lead to dyslipidemia. The advanced dyslipidemia can progress the atherosclerosis and ultimately Cardio-Vascular Disease (CVD), commonest cause of death in type 2 diabetics.

\section{REFERENCES}

American Diabetes Association. 2007. Standards of Medical Care in Diabetes. Diabetes Care, 30: 4-41.

Frank, B, Stampfer, J, Steven, M. 2002. Elevated risk of cardiovascular disease prior to clinical diagnosis of type 2 diabetes. Diabetes Care, 25: 1129-34.

Sridhar, RG. 2002. Diabetes in India: snapshot of a panorama. Current Science, 83: 1-2.

Car, J, Patel, H, Majeed, A. 2004. Diabetes care in developing countries. Can. Med .Assoc. J., 176: 209-12.

Khatit, M, Quazi, S. 2008. Risk factors of type 2 diabetes mellitus in rural wardha: a community bared study. International Journal of Diabetes in Developing Countries, 28: 79-82.

Analava, M., Bhattacharya, D. 2007. Dietary Influence on Type 2 Diabetes (NIDDM). J. Hum. Ecod; 21:139-47.

Goldfine and Beckman: 2008. Life and Death in Denmark: Lesson About Diabetes and Coronary Heart Disease. Circulation, 117: 1914-7.

Mozaffarian, D., Martijn, B., Alberto, A., Mer, J. 2006. Trans Fatty Acids and cardiovascular diseases. NEJM, 354: 1601-13.

Ronald, M, Krauss, M. 2004. Lipids and Lipoproteins in Patients with type 2
Diabetes. Diabetes Care, 27: 14961504.

Mohsin, R., Badar, B., Saeed, A., Rehman, A. 2007. Type 2 Diabetes: the relationship between the serum cholesterol and triglycerides.

Professional M Ed J., 14: 337-43.

Alexander, C.M., Landsman, P.B., Tentsch, S.M. 2003. Third National Health and Nutritional Examination Survey (NHANES III), National Cholesterol Education Program (NCEP). NCEP defined metabolic syndrome, diabetes, and prevalence of coronary heart disease among NHANES III participants age 50 years and older diabetes. 52: 1210-4.

Haffner, S.M., Lehto, S., Ronnemaa, T. 2000. Mortality from coronary heart disease in subjects with type 2 , diabetes and in non diabetic subjects with and without prior myocardial infarction. N. Engl. J. Med., 339: 229-34.

Harris, S.B., Ekoe, J.M., Zanowiez, Y. 2005. Glycemic control and morbidity in the Canadian primary care setting (Result of the diabetes in Canada evaluation study). Diabetes Resllin. Pract., 70: 907.

Guzder, R.N., Gatting, W., Mullee, M.A. 2005. Prognostic value of the framingham cardiovascular risk equation and the UKPDS risk engine for coronary heart disease in newly diagnosed type-2 diabetes: Results from a united kingdom study. Diabetes Med., 22: 554-62.

Talat, N., Khan, A., Gulsena, M., Bilal, B. 2003. Dyslipidemias in Type 2 Diabetes Mellitus Patients in a Teaching Hospital of Lahore, Pakistan. Pak. J. Med. Sci., 19: $283-6$.

Berrios, X, Koponen, T., Huiguang, T, Khaltaev, N., Puska, P., Nissinen, A. 1997. Distribution and prevalence of major risk factors of non-communicable diseases in selected countries: the WHO 
Inter-Health Programme. Bull. World Health Organ, 75: 99-108.

Goldberg, I.J. 2001. Clinical review 124: Diabetic dyslipidemia: causes and consequences. J. Clin. Endocrinol. Metab. 86: 965-971.

Haffner, S.M. 1998. Management of dyslipidemia in adults with diabetes. Diabetes Care, 21: 160-78.

Juutilainen, A., Lehto, S., Ronnemaa, T., Pyorala, K., Laakso, M. 2005. Type 2 diabetes as a "coronary heart disease equivalent": an 18-year prospective population-based study in Finnish subjects. Diabetes Care, 28: 2901-2907. Wood, P.D., Stern, M.P., Silvers, A., Reaven, G.M, von der Groeben, J. 1972. Prevalence of plasma lipoprotein abnormalities in a free-living population of the Central Valley, California. Circulation, 45: 114-126.

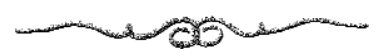

